\title{
Formación y gusto por la escritura y la lectura a luz de las ideas de Friedrich \\ Nietzsche como ámbito de estudio de la Educación Corporal
}

\section{Formação e gosto pela escrita e leitura à luz das ideias de Friedrich Nietzsche como um campo de estudo da Educação Corporal}

\section{Education and taste for writing and reading in the light of the ideas of Friedrich Nietzsche as a field of study of Body Education}

\author{
Carmen Emilia García Gutiérrez ${ }^{1}$ \\ Andrés Felipe Correa Castaño ${ }^{2}$
}

\begin{abstract}
RESUMEN
En este artículo estamos presentando un tema de estudio: la Educación Corporal. Tratamos de leer a Federico Nietzsche a la luz de las ideas de gusto, cuerpo y educación con el interés de abrir horizontes de interpretación para un escenario académico necesitado de una (otra) significación. Recurrimos al pensamiento de Nietzsche con el fin de abordar objetos que él propiamente no llegó a explorar nunca como son la formación del gusto desde el cuerpo en perspectiva pedagógica y hacia una Educación Corporal.

${ }^{1}$ Magíster en Educación y Desarrollo Humano. Profesora de la Universidad de Antioquia, Colombia. E-mail: carmenemiliagarcia@yahoo.es.

${ }^{2}$ Magíster en Motricidad - Desarrollo Humano. Profesor de la Universidad de Antioquia, Colombia. E-mail: abedel1982@hotmail.com.

Profesores del grupo de investigación Estudios en Educación Corporal.
\end{abstract}


Encontramos que los conceptos de formación del gusto y de cuerpo nos sirven como herramientas analíticas para nuestra investigación.

Palabras-clave: sentido histórico; lectura; escritura; formación del gusto; сиегро.

\title{
RESUMO
}

Neste artigo, apresentamos como tema de estudo a Educação Corporal. Trata-se de ler Friedrich Nietzsche à luz das ideias de gosto, corpo e educação, com o interesse de abrir os horizontes de interpretação para um cenário acadêmico necessitado de (outra) significação. Recorremos ao pensamento de Nietzsche para abordar assuntos que ele, propriamente, nunca chegou a explorar, como a formação do gosto a partir do corpo numa perspectiva pedagógica em direção a uma Educação Corporal. Em nossa pesquisa, os conceitos de formação do gosto e de corpo nos servem como ferramentas analíticas.

Palavras-chave: sentido histórico; leitura; escritura; formação do gosto; corpo.

\begin{abstract}
In this article we are presenting a topic of study referred as body education. We have read Friedrich Nietzsche in the light of the ideas of taste, body and education, with the interest of expanding the horizons of interpretation for an academic setting in need of a (another) meaning. We have appealed to Nietzsche's thought in order to approach study objects he never explored properly, such as the formation of taste from the body in a pedagogical perspective and towards a body education. We have discovered that the concepts of taste formation and body may serve as analytical tools for our research.
\end{abstract}

Keywords: historical meaning; reading; writing; taste formation; body. 


\section{Por un gusto excepcional}

Nosotros somos la excepción y el peligro; nosotros tenemos necesidad de defendernos constantemente. Pero, con todo, se puede abogar en favor de la excepción, con tal de que no pretenda convertirse en regla.

(NIETZSCHE, 2001).

Nietzsche no busca formar un gusto por leer, por escribir y por los clásicos para ser más inteligentes, ni para ser más útiles, ni para producir siempre que se actúa. La historia, la escritura y la lectura están dirigidas principalmente a que cada hombre se forme como espíritu libre en lo que éste tiene de original y de distinto. Estos tres componentes se figuran como cinceles que pulen y dan forma a un bloque de yeso que vendría a ser el estudiante. Es decir, el "yo" sólido se vulnera porque se aventura en cada acto, porque deviene, ya que, para llegar a ser lo que se es, primero se debe trasegar por diferentes roles constituyentes de esa idea de hombre superior.

El hombre de gusto excepcional dirige sus acciones contra el presente. Su situación es de contradicción con el hoy. Sabe qué ideales animan su época y logra percibir los síntomas que debilitan al hombre. Pero no solo diagnostica sino, también, qué prescribe este médico de los hombres. Su carácter afirmativo busca crear una nueva grandeza del hombre. Para esto debe romper las tablas de valores para escribir sobre ellas nuevos valores. ¿En qué consiste tal grandeza? Señalando primero aquello que lo empequeñece, a saber: la pereza, la comodidad, la hipocresía y el dejarse guiar dócilmente. La grandeza del hombre, según el carácter afirmativo nietzscheano, es el resultado de un disponerse a la amplitud. Cuántas situaciones diferentes puede soportar, conocer, develar y transformar en función propia. Esta grandeza y fortaleza es la que posibilita que el hombre esté en capacidad de asumir tareas largas. No hay gusto por lo inmediato, por lo instantáneo, sino por aquello que nace de un arduo, paciente y prolongado trabajo. Un gusto para sí, para la diferencia, evadiendo la repetición, siendo divergente, acompañado por categorías que no hablen ya de lo "bueno" ni de lo "malo" sino más bien, de lo plural, lo profundo, lo amplio.

Hacemos nuestra, en un sentido educativo, la sentencia que Nietzsche (1997, p. 166) dirige a los filósofos y nosotros desplazamos al caso del estudiante universitario que está más cerca de ser identificado por un solo lenguaje, por un solo rostro, por una sola función, que por un personaje cubierto por muchas máscaras: Acaso para la educación del verdadero filósofo se necesite que él mismo 
haya estado alguna vez también en todos esos niveles en los que permanecen, en los que tienen que permanecer sus servidores, los trabajadores científicos de la filosofía; él mismo tiene que haber sido tal vez crítico y escéptico y dogmático e historiador y, además, poeta y coleccionista y viajero y adivinador de enigmas y moralista y vidente y "espíritu libre" y casi todas las cosas, a fin de recorrer el círculo entero de los valores y de los sentimientos valorativos y a fin de poder mirar con muchos ojos y conciencias, desde la altura hacia toda lejanía, desde la profundidad hacia toda altura, desde el rincón hacia toda amplitud.

No nos podemos confundir cuando se piensa la formación del gusto como selectividad. Decir no a muchas cosas no es lo mismo que decirle no a lo nuevo. A qué decirle sí y a qué decirle no es a lo que la formación del gusto apunta. Decirle no a la creencia, a la fe, pero también a la inmodestia filosófica y científica que pretende ingenuamente dar fundamentos de lo que algo es. El gusto nunca es unifocal, no es incondicional consigo mismo. El buen gusto cambia porque la voluntad busca superar el momento actual. El gusto deviene, el individuo se metamorfosea, los valores se transvaloran. El gusto formado, al devenir, no busca cambiar de opinión, esto no es suficiente. El elemento es el objetivo a cambiar guiado por la voluntad de poder en su cualidad afirmativa. La afirmación de la vida, es precisamente, la afirmación de lo múltiple, de lo mutable e inacabado. Para esto el buen gusto nos dota de travesura, de espíritu investigativo, de contemplación interesada, de objeciones, de la desconfianza jovial.

\section{Formación del gusto en el estudio de los clásicos}

Por una mirada impulsiva. El problema del hombre moderno que estudia a los clásicos es un problema de estilo en el sentido que desprecia la forma a favor del contenido (NIETZSCHE, 2003, p. 69). Se quiere formar un interior (conocimiento) a expensas de un exterior (movimiento-conquista-vida). Este contraste justifica la crítica de Nietzsche a una filología que recolecta datos pero no siembra acciones. Nietzsche nos invita a nutrirnos de la historia con apetencia: con apetito de acción. Alimentarnos de historia cuando aún no tenemos hambre, sino que absorbiéndola porque "es importante para la formación" niega la formación misma. La historia es un alimento al cual nos lanzamos con la fuerza de la necesidad, tomando lo justo, dándonos energía, impulsándonos hacia afuera, evitando los excesos.

Acumular, comer bulímicamente, a esto no apunta la formación. Lo que el hombre moderno consideró como formación no es sino un "tipo de saber secun- 
dario de la formación, pues se detiene en los pensamientos sobre la formación, en los sentimientos sobre esta, pero sin producirse ninguna decisión formativa al respecto" (NIETZSCHE, 2003, p. 69).

El estudio de los clásicos no representa más que una acción convencional y una falsificación porque se los mira con los ojos del presente sin la capacidad de olvidar la propia cultura. Lo que no implica interpretar desde el punto cero (esto implicaría una inmensa contradicción de la lectura de los textos de Nietzsche y su idea de perspectivismo), sino identificar los valores del presente que valoran a los clásicos como letra muerta.

Decimos pues que alimentarse sin hambre indigesta y paraliza el cuerpo. Tener formación histórica no es lo mismo que saber de historia. Esta es la incomprensión del hombre moderno. Por eso dice Nietzsche (2003, p. 70), que si un griego les observara en su manera de actuar, vería que un hombre culto y un hombre históricamente culto a la manera moderna no se verían diferentes: $\mathrm{Y}$ es que ese conocido pueblo de un pasado no demasiado remoto, el griego, en su periodo de mayor poderío, mantuvo un tenaz sentido a-histórico.

Si por medio de un encantamiento tuviera un hombre de nuestro tiempo que regresar a esa época, muy posiblemente encontraría a los griegos muy "incultos", con lo cual el secreto meticulosamente guardado de la formación moderna ciertamente se destaparía a la risa pública.

Enciclopedias ambulantes, serpientes explayadas, así quiere la modernidad formar al hombre a través de los estudios históricos. Formar el gusto en el estudio de los clásicos no significa retroceder sino levantarse: levantar la mirada, ver desde arriba. Y segundo, no es un mirar para atrás, solamente, sino, mirar hacia delante. Estudiar los clásicos implica construir un puente entre el pasado y el presente. Cuando a través de la historia realizamos un viaje retrospectivo hacia aquellos lugares y personajes que han representado las más "altas" y "fuertes" expresiones de su época, no es para manipularlos como hechos, sino como faros que han de guiar las posteriores acciones del hombre actual. "[...] así es como aprenderás de la manera más segura en qué dirección toda la humanidad futura no tiene ya posibilidad ni derecho a ir [...]" (NIETZSCHE, 2005b, p. 209).

Es el sentido filosófico el que encontramos en el contacto de Nietzsche con la historia, ¡no el filológico! Es la filosofía la que le evita a Nietzsche mirar a Grecia como un dato, como un hecho, con la mirada escrutadora del anticuario. Lo que Nietzsche pretendía con este estudio era reconstruir los hechos con la determinación de convertirlos en un estímulo para la propia vida. El interés de Nietzsche en su encuentro con Grecia no era describir los detalles de su cultura, sino, identificar la sustancia vital que sirviera como horizonte de civilización: 
Para Nietzsche la filología oficial, aunque base fundamental de la educación prusiana, no era de largo alcance, pues no preparaba para la ciencia ni para la vida, al proyectar en la Antigüedad un pensamiento pequeño-burgués, inducido por una sociedad filistea que esperaba del filólogo el fomento y la difusión de un humanismo superficial. El joven buscaba huir a toda costa de dicha tendencia (SALCIDO, 2008, p. 8).

Nietzsche temía convertirse en un especialista. Lo que la filología estaba disminuyendo en él era su libre sensibilidad y el sentido filosófico que supo mantener gracias a la lectura de Schopenhauer. La historia en Nietzsche, como medio para estudiar a los clásicos, forma una mirada impulsiva. Mirar históricamente es tomar impulso, dar unos pasos hacia atrás para luego lanzarse sobre el presente y distinguir el juego de la balanza.

La formación del gusto asume la historia para problematizar la moral, para denunciar cualquier intento de fundamentación. Por el contrario, la historia científica, objetiva, al buscar un fundamento de la moral no sólo cree en una moral vigente sino que se siente en la obligación de asumirla. La ciencia del mal gusto, que no acude a la historia, reproduce $s u$ moral a tal punto de resultar impensable problematizarla. La ciencia para Nietzsche no define sino que describe. No asegura sino que problematiza. Sus afirmaciones no dejan de ser "provisionales". Compara morales, camina a través de las épocas en busca de las diferenciaciones de valor (dónde ha predominado lo negador o afirmador de la vida). El gusto historiza en busca de sentidos y no de certezas.

Una actitud teórica que apuesta su esfuerzo intelectual al poder creador de la descripción, con la cual se pueden poner al descubierto tantos hechos soterrados por quienes han dispuesto del poder de dictaminar lo que debe considerarse como verdadero [...] Una actitud que no cree que la descripción sea ni se agote, sin más, en la mera recolección de datos y hechos aplanadores de la riqueza de vivencias profundas o elevadas del espíritu humano [...] (JARA, 1998, p. 234).

La formación del gusto, en su conexión con las producciones científicas, puede identificar la "voluntad de verdad" en su lenguaje presuntuoso. El gusto, con todo lo riguroso que pueda llegar a ser no olvida la modestia. Nietzsche descubre cómo el "tú debes" de la moral se desplaza al ámbito de la ciencia, que en función de la moral, "demuestra" de qué están hechos los fundamentos. 
El gusto por los fundamentos es lo que critica Nietzsche, y lo hace señalando los sedimentos culturales de que están impregnados tales cimientos. ¿Quién fundamenta, cuándo lo hace, dónde está ubicado, qué ha olvidado? Es por esto que tales fundamentos se consideran arbitrarios y fortuitos, hijos legítimos de su época y legitimadores de la moral dominante. Porque ha faltado el ejercicio problematizador, cuestionador de la misma moral y del mismo que fundamenta. "¿Quiénes somos?" es la pregunta que ha hecho falta a los representantes de la ciencia: Justo porque estaban mal informados e incluso sentían poca curiosidad por conocer pueblos, épocas, tiempos pretéritos, no llegaron a ver en absoluto los auténticos problemas de la moral: - los cuales no emergen más que cuando se realiza una comparación de muchas morales (NIETZSCHE, 1997, p. 123).

¿Cómo sería una formación del gusto en su carácter más modesto que discrepe del espíritu antes mencionado de la ciencia como moral? La investigación guiada por el gusto excepcional no busca cristalizar el objeto de estudio, sino, recogerlos, problematizarlos, clasificarlos logrando determinar las diferenciaciones de valor. Tal objeto de estudio es un material que ha tenido una procedencia, un crecimiento, una metamorfosis. Lo que el gusto pretende acá es "una tipología de la moral" (NIETZSCHE, 1997, p. 123). La formación del hombre ha estado guiada por la intención demostrativa de los pensadores europeos. Su afán de demostrar, su gusto fijado, su cuerpo sedentario, su pensamiento actualizado, terminaron por implantar horizontes limitados, logrando así el "estrechamiento de la perspectiva" (NIETZSCHE, 1997, p. 128).

\section{La formación del gusto en la escritura}

La escritura formada por el gusto viene a ser el síntoma de un cuerpo que ha compactado sobre sí una serie de observaciones y experiencias. El sentido de la escritura, el para qué de la escritura, se puede entender desde Nietzsche como la expresión de una búsqueda de sí mismo introduciendo en el papel no solo los pensamientos fruto de un racionalismo, sino también lo que es producto del deseo, del temor, del querer y del sentir. La escritura nietzscheana, ya lo hemos comentado, se escribe con "sangre", lo que implica una especie de inseparabilidad entre la escritura y la vida como devenir. Lo que el estudiante ha de escribir tendrá que asemejarse a un estanque de peses (NIETZSCHE, 2005a, p. 179). Palabras móviles y vivas porque hablan desde el cuerpo.

Forma y contenido remiten al cuerpo y al espíritu de quien escribe. Por eso decimos que la escritura y el pensamiento son síntomas del cuerpo. La escritura 
da cuenta de uno. Lo que no significa hablar solamente de uno separado del mundo en una especie de solipsismo. El sentido de la escritura es la afirmación de uno mismo. Pero afirmar no significa testificar, sino lo contrario, aprender a preguntar primero, a sospechar, a dudar de todo y a criticarlo todo.

Escribir tampoco es repetir al otro, imitar al otro, ni venerarlo, sino, apoyarse en él para saltar a un territorio diferente del inicio. Es de esta manera como la escritura implica una fuga de los lugares recorridos que aún se hayan plasmados en la piel a modo de cicatriz. Hablar de la escritura como necesidad. "El libro debe pedir pluma, tinta y escritorio; pero generalmente son la pluma, la mesa y el escritorio los que piden el libro. Por eso los libros de hoy son tan poco valiosos" (NIETZSCHE, 2005a, p. 99).

La búsqueda de sí mismo, o llegar a ser el que se es, implica una conquista de sí, y esto conduce siempre a una lucha. La escritura es pues, también, la expresión de una lucha. Una batalla que se expresa a través de conceptos críticos y transvaloradores, otorgándoles un sentido múltiple. De otro modo sería una instrucción directa que poco añadiría a la lucha del individuo por su singularidad. La escritura es el lugar donde el cuerpo se hace visible para denunciar lo subterráneo. Quiere desnudar quimeras y vestirlas con otros ropajes. Un hombre así formado no puede escribir sobre lo más visible, lo más repasado, ni escribe para realizar un reconocimiento de lo harto reconocido, sino que escribe sobre lo que está oculto.

En Nietzsche la escritura es "dinamita", porque él quiere hacer estallar algo que está demasiado sólido, demasiado petrificado o cristalizado. La escritura activa siempre redunda en conmoción de la vida, y la vida no la podemos separar entre un interior y un exterior. Es decir, no es un asunto privado ni desvinculado de las dinámicas sociales.

En el caso que nos compete, hay un interés en Nietzsche por replantear la manera como se enseña a escribir en la universidad debido a una serie de valores que el logra diagnosticar como provenientes de una cultura al servicio del Estado. Esta es la escritura rápida, útil, veneradora. La formación del gusto en la escritura no es el modo de expresión de un estudiante que "quiere darse a entender".

No remite a la intención de hacer visible, de demostrar algo que él está pensando. Y mucho menos se puede entender la escritura como un producto despersonalizado, neutral, objetivo.

Escribir así es un desinterés hacia sí mismo, un derroche de energía dirigido hacia otras instancias que no son la persona misma. Porque la escritura incita a la acción y ésta es siempre una composición que recae sobre el autor.

Se escribe para desnudarse en el papel. El tono despersonalizado de la escritura universitaria consiste en escribir en un cuaderno lo que alguien alguna 
vez escribió en un libro para luego escribirlo, lo más parecido posible, en un examen. La formación en la escritura de buen gusto involucra, antes que nada, la formación de una actitud en el estudiante: el reconocimiento de la inmadurez, la modestia, la paciencia, la concentración, el gusto por el trabajo arduo. Es un largo recorrido el que precisa el estudiante para adquirir una escritura con sangre: "Hagamos mil y más proyectos de novelas, que no rebasen de dos páginas, pero escritas con tal propiedad que toda palabra sea necesaria; escribamos cada día anécdotas, hasta que se aprenda a hallar la forma más plena, más eficaz". (NIETZSCHE, 2005b, p. 142).

Pero también decimos que quien escribe es alguien que se expone, que camina, que produce una escritura fruto de un trasegar, de un Fläneur peligroso en busca de afectos. Ross (1994, p. 538) nos comenta cómo dentro de la cotidianidad de Nietzsche, se integraba una caminada diaria de cuatro horas con el cuaderno de apuntes en mano. La escritura con pies ligeros debe evitar la cobardía de habitar un solo lugar. Si Nietzsche criticó la educación por estar bajo el influjo de la cultura periodística con todo lo floja por estar solo al servicio de la actualidad, qué pensaría de los periodistas omnisatisfechos con la presencia del portátil en sus siempre habitadas oficinas de redacción.

La escritura es producto de una serie de afectaciones que se asumen como constituyentes de una nueva perspectiva. Lo que se expresa es el juego del cuerpo en autoexposición y autorrealización. El territorio de la escritura no es el escritorio y su referente no es, solamente, los libros. Nietzsche quiere escritores que caminen, que se expongan a nuevos territorios luego de haberse apropiado de sus lugares iníciales. Este territorio, indiscutiblemente es también el territorio de la lengua materna y la lengua griega y latina. Porque son ellas, con sus conceptos profundos, con la dedicación gramatical, por la preocupación por el sentido y necesidad de cada palabra que deben convertirse en la patria lingüística del estudiante formado en el gusto por la escritura.

Hemos dicho por un lado, que desde Nietzsche, la educación precisa de la formación para que el hombre eleve su existencia, para que alcance su singularidad. Por el otro, decimos que el gusto es una red elástica que discierne lo que nos debilita o fortalece. Formar en el gusto no es lo mismo que educar a una persona para que le agrade escribir, para que deje de ser un "vago" y escriba, porque escribir es ¡muy importante! Formar en el gusto tampoco trata sobre cómo se debe escribir, en un sentido gramático, ortográfico. No se trata de aprender las reglas internas de la escritura. Lo que no disminuye su importancia. Pero no es eso. La formación del gusto en la escritura tiene la intención de producir un medio de expresión de pensamientos, de experiencias, de críticas, de nuevas valoraciones, a través de un estilo propio, todo esto no al servicio exclusivo del Estado, sino al servicio de la propia transformación como acceso al paisaje de una cultura superior. 


\section{El estilo de Nietzsche}

Si entendemos el estilo como "la manera de", la "forma", el "cómo", o aun más relevante según las palabras de Susan Sontag (2007, p. 32) cuando nos dice que "[...] nuestra manera de expresarnos es nuestra manera de ser. La máscara es el rostro", diremos que en Nietzsche el estilo de su escritura es el reflejo de su espíritu abierto, enigmático. Su estilo es abierto y lucha contra todo dogmatismo del pensamiento, tratando de evitar caer en la instrucción directa y su consecuente memorización. En un sentido pedagógico, el estilo abierto es una sustancia que anima, no ha obedecer, sino a realizar las propias conquistas, a fortalecer el espíritu de la investigación. El estilo abierto se convierte al mismo tiempo en una barrera y un catalizador para los lectores debido a las imágenes que nos propone. Barrera debido a la incomprensibilidad segura que tendremos de una lectura rápida de sus textos. Con el estilo enigmático, pictórico, Nietzsche está seleccionando los lectores de sus libros. Lectores pacientes, tranquilos, profundos. Y es un catalizador debido a que las imágenes permiten una lectura múltiple de sus textos. No una verdad absoluta sino una pluralidad de sentidos se hallan en sus palabras que nos permiten no solo identificar sus luchas sino también las intenciones respecto a sus lectores. Las intenciones son de motivación, de ánimo a emprender las propias búsquedas.

Debemos precisar que la obra de Nietzsche no presenta un solo estilo. Por ejemplo, Humano, demasiado humano es un libro de "sentencias" y no de aforismos. Las sentencias remiten a un estilo cerrado en contraposición a la apertura del aforismo. Según Ross (1994, p. 538):

Los nuevos apuntes llevan como título "Reja de arado" de evidente simbolismo: la reja del arado abre la tierra dura para que se pueda sembrar en ella; para poder recoger el fruto, primero hay que sufrir y hacer sufrir. Pero la "reja de arado" está prevista como escritura cerrada [...] Nietzsche sigue desconfiando de la forma, más abierta, basada en la secuencia de aforismos. La "reja del arado" está proyectada todavía como un conjunto coherente en la forma, como un "libro de sentencias".

Por otro lado, el estilo nietzscheano critica la desvinculación del sujeto de su propia creación por lo que nos sugiere la importancia de crear un modo de expresión con base en la vida propia. Se escriben los pensamientos, pero también, 
los afectos, las intuiciones, las sensibilidades. Nietzsche, como modelo, escribe con su sangre, con sus dolores y esperanzas una filosofía que sitúa el cuerpo, no como tema de reflexión, sino como hilo conductor de la filosofía. El escritor nietzscheano no es un sujeto puro, cuya máxima expresión es el pensamiento, excluyendo de esta dimensión formativa la voluntad, el dolor y el tiempo.

La escritura, el cuerpo, la vida hacen parte de un estilo que podríamos atrevernos a llamar inmanente. El estilo remite al cuerpo en tanto fragmentado, incompleto, incierto, apasionado.

La manera de Nietzsche presentarnos sus pensamientos no son menos válidas que los pensamientos mismos. La manera delata una intención. Su intención es formativa en tanto según la forma como nos vayamos expresando se evidenciará un devenir en la escritura y en la vida del sujeto. "Corregir el estilo es corregir el pensamiento, sin más. Quien no se convenza de esto en primer momento no llegara a convencerse nunca" (NIETZSCHE, 2005, p. 99).

Desde un ámbito universitario y formativo diremos que el estudiante formado para la escritura primero debe reconocer la necesidad de aprender un estilo, de acomodarse a estilos ajenos, de entenderlos como norma. La adopción de un estilo propio, del sello que lo caracterice de otros estilos solo se da por medio de la adopción e imitación de estilos ajenos. La madurez del estilo no implica un solipsismo sino que expresa la capacidad que tuvo el escritor de juntar dentro de sí muchos estilos. Sólo los estilos liberan el estilo" (CARRIZOSA, 2000, p. 31).

Formar para escribir desde el cuerpo no significa hablar solo de mí cuerpo, de mis opiniones, sino demostrar cómo el cuerpo presenta a su vez una compleja variedad de pliegues que lo constituyen y lo derrumban. Es decir, toda escritura es síntoma de un cuerpo particular, por lo cual, es natural preguntarse por la perspectiva que se plasmó en determinado escrito, por la fuerza que dirigió esa labor. El hombre se forma con base en perspectivas, no en verdades absolutas. Quien escribe ha de saber que su obra es una expresión en perspectiva. Que se escribe desde un lugar, desde un marco. Que su intención no es dogmática.

\section{Crítica a la enseñanza de la escritura}

El escritor avestruz lo hace apresuradamente: una, dos, cien, mil páginas pueden ser arrasadas por su pluma veloz, por sus dedos productores de resultados. Se escribe rápido en la universidad como se produce rápido en la empresa, ambos veloces como el avestruz, y como ella, con la cabeza enterrada. Lo que no alcanza a intuir este tipo de formación al servicio del Estado que produce estudiantes de exportación y que demanda celeridad manual, mental 
y corporal, es el sentido de la escritura. El "para qué" y "cómo" de la escritura y el tiempo de la escritura. La escritura, dentro de una cultura de lo inmediato, de la producción en serie, sufre las consecuencias de generar un conocimiento mediocre, irreflexivo e imitador. Además de:

[...] la tendencia a producir de modo apresurado y vanidoso, la manía despreciable de escribir libros, la completa falta de estilo, un modo de expresarse que no se ha refinado, que carece de carácter o pobremente afectado, la pérdida de cualquier canon estético, el deleite en la anarquía y el caos, en resumen, todos los rasgos literarios de nuestro periodismo y al mismo tiempo de nuestro mundo académico (NIETZSCHE, 1980, p. 79).

Lo que a la formación está llamada, no es sólo a contemplar las leyes de la gramática, sino también, a describir el tipo de estudiantes que están educando. Así lograran distinguir que a éstos los mueve un poderoso deseo de escribir guiado por la ambición y la ignorancia de su situación como principiante. Escribir, como expresión del estudiante universitario, antes de ser un derecho, es un deber. La universidad al no reprime esta ambición, terminó por respetar la libre expresión del estudiante permitiendo que éste utilice el lenguaje escrito de cualquier manera. Lo que escribe tal estudiante no dejan de ser meras opiniones, ligerezas sobre los temas más profundos.

El estudiante debe ser comprendido como un ser inacabado que precisa de formación en la escritura y no realizar concesiones en momentos tan prematuros de su educación. Pero el problema que nos plantea Nietzsche es que la falta de egoísmo impide que los profesores guíen de la mejor manera a sus estudiantes en el ámbito de la escritura. La falta de egoísmo se expresa en que todo lo que producen está pensado para ser comunicado. Escriben para los otros pero no para su propio uso. Esta falta de interés en la escritura por parte de los profesores los termina convirtiendo en pasadizos del saber por donde transita el conocimiento sin hacer ninguna parada en ellos mismos: Ya no piensa en él, sino en el escritor y en su público; desea la comprensión, pero no para su propio uso. El que enseña es la mayoría de las veces incapaz de hacer cualquier tarea propia para su propio bien; piensa siempre en el bien de sus alumnos y ningún conocimiento le proporciona placer sino en tanto que pueda enseñarlo. (NIETZSCHE, 2005b, p. 154).

Nietzsche considera que el estudiante debe someterse a la guía del profesor, quien le enseñará a tratar de un modo más profundo su propia lengua de la manera como lo hacía en la Antigüedad. Es decir, introduciéndose en los 
conceptos, en busca de ideas que hablen al presente y al futuro. Así se logra entender la lengua como algo vivo y no como un dato estático y empolvado. "Tomad en serio vuestro idioma" es el imperativo que Nietzsche dirige sobre las escuelas y universidades. Éstas han hecho dirigir la mirada al estudiante demasiado rápido hacia otras geografías lingüísticas sin recorrer el propio territorio. El poliglotismo es un peligro que Nietzsche diagnostica al ver en esta tendencia una preocupación por conocer palabras, más no, ideas. Por estar a la altura de los tiempos, conociendo muchos idiomas, lo que ha logrado el escritor avestruz, es enterrar su cabeza en la tierra sin conocer las alturas formativas del paisaje de la Antigüedad. "Sólo tras haberse hecho auténtico ciudadano de una patria lingüística, es lícito al espíritu empezar a viajar a los universos de otras lenguas" (CARRIZOSA, 2000, p. 32).

¿En qué consistiría este uso sentido práctico de la formación del gusto por la escritura? De nuevo aparece el concepto de gusto como autodefensa y al mismo tiempo, aparece la red elástica que acoge la lengua materna como modelo:

Si no conseguís obtener ese resultado por vosotros mismos, es decir, sentir desagrado físico frente a ciertas palabras y a ciertas frases de nuestra jerga periodística, abandonad al instante las aspiraciones a la cultura [...] el mismo profesor, al referirse a nuestros autores clásicos, debería mostrar, renglón a renglón, el enorme cuidado y rigor con que hay que entender todas las expresiones, cuando se tiene un auténtico sentimiento artístico, y cuando se aspira a la completa claridad de lo que se escribe (NIETZSCHE, 1980, p. 73).

\section{Formación del gusto en la lectura}

El lector nietzscheano se caracteriza por su volatilidad, por la capacidad de hacer saltar su cuerpo de los lugares que siempre buscan anclarlo. A través de esta vía, del preguntarse por uno mismo, es que se puede llegar a ser un lector de buen gusto. Para saber a qué dificultades procedentes del pasado debe enfrentarse el estudiante. Al respecto, Jorge Larrosa argumenta que

[...] el "yo" del lector no es otra cosa que el resultado superficial de una cierta organización jerarquizada de fuerzas que en gran medida permanece inconsciente. Lo que somos capaces de leer en un libro es el resultado de 
nuestras disposiciones anímicas más profundas. Por eso lo que leemos y el modo como lo leemos es un síntoma que revela eso que somos y que permanece desconocido incluso para nosotros mismos: nuestras características tipológicas. Es decir, la finura y el carácter de nuestros sentidos, nuestras disposiciones corporales, nuestras vivencias pasadas, nuestros instintos, nuestro temperamento esencial, la calidad de nuestras entrañas (LARROSA, 1996, p. 227).

La mirada se ve atravesada por el eje tiempo y espacio. Se educa la mirada a través de un ritmo de trabajo lento y también reubicándola en espacios desconocidos. Dirigirla a lugares desconocidos, con preguntas inéditas y con comparaciones extrañas. La volatilidad del lector libre supone la posibilidad de nuevas perspectivas, de nuevas alianzas entre diferentes fuentes de conocimiento. "En ese caso, podría, desde luego, abandonarse y con la mayor confianza dejarse guiar por el autor [...]" (NIETZSCHE, 1980, p. 33). Se es una excepción porque no se cumple con la regla. ¿Cuál es la regla en el ámbito universitario? Ser un profesional incondicional con su conocimiento. Dos derechos posee el lector nietzscheano: el derecho al silencio y el derecho a olvidar. El primero, ya lo dijimos, para permitir la entrada de nuevas perspectivas; el segundo, para crear. No puede haber acción si aun se sigue atado al texto.

La formación del gusto por leer en Nietzsche se puede entender como la acción de una autoridad que implanta en sus estudiantes la necesidad de apertura y autodefensa contra los libros. Leemos apreciando las diferentes perspectivas pero sabiendo distinguir las producciones mediocres que enferman. La formación del gusto por la lectura enseña a tomar distancia frente a la "charlatanería actual" y al mismo tiempo, a variar la lectura para evitar el instinto de conservación. Leer siempre lo mismo es un síntoma de tal instinto.

\section{La lectura como apertura}

¿Por qué la apertura? Porque esta cualidad del gusto en la lectura tiene el poder de generar una nueva configuración personal. La lectura es una mirada para fundar otra mirada. Se es uno antes de la lectura y otro después de la lectura. La formación del gusto por la lectura entiende los libros como caja de herramientas, o como personajes que nos sirven de plataforma para enfrentar los

problemas que nos competen. El sentido de esta formación no es el utilitarismo 
o la producción en serie como lo ha entendido el Estado y por extensión, la universidad. El sentido de tal apertura es la búsqueda de sí mismo singular en tanto que plural. "Quizá el arte de la educación no sea otro que el arte de hacer que cada uno llegué hasta sí mismo, hasta su propia altura, hasta la mejor de sus posibilidades. Algo, desde luego, que no se puede hacer al modo técnico ni al modo masivo" (LARROSA, 1996, p. 259).

Cada libro es un sol que ilumina al estudiante, que le da un color y tonalidad diferente (NIETZSCHE 1997, p. 173). La función de la apertura en la lectura es el de dar múltiples colores al lector. Entendamos por colores: morales, pensamientos, acciones, perspectivas. Es en la medida que la formación del gusto ubique al estudiante en un cielo estrellado, es que se irá resistiendo contra las fuerzas niveladoras de la educación guiada por los valores del Estado. Así pasará por el gusto de lo Uno al gusto de lo múltiple. El gusto le permitirá mirar de arriba abajo y no al contrario, como lo hace la "perspectiva de la rana" (NIETZSCHE, 1997, p. 24).

La formación así entendida busca la triada lectura-herida-transformación. La formación del gusto dispone diferentes lecturas para crear una atmósfera alrededor del estudiante. ¿Qué tipo de afecciones puede manifestar un estudiante en tal ambiente escrito? El miedo y el dolor ante lo desconocido, la incertidumbre que siempre aparece ante un territorio inédito y problemático. Esta atmósfera busca herir, vulnerar su situación actual. "[...] el deber del educador es causarle heridas o aprovechar las que le cause el destino, y cuando así el dolor y la necesidad hayan nacido, pueda haber en los puntos dañados inoculación de algo nuevo y noble" (NIETZSCHE, 2005b, p. 170).

El gusto por leer no debe entenderse como un deseo de apropiación de datos o hechos característico del lector erudito o del filólogo. Nos referimos, más bien, al gusto por destruir y producir algo con esa lectura. En Nietzsche destruir no se separa del construir. La crítica no interesa si no deviene en transvaloración. La apertura, el movimiento elástico, rompe lo que está cristalizado. Y por medio de tal movimiento lo que se quiebra adquiere nueva forma. Sabe Nietzsche que en el cuerpo de sus lectores siempre se libra una batalla, siempre hay un juego de fuerzas dinámico. Se lee para construir, para valorar, y no solo para realizar comentarios de la obra. Lo interesante sucede por fuera del texto, es decir, en un contexto extra-textual que viene animado desde el texto. La escritura es una acción para la acción.

La apertura, como cualidad del gusto, también lucha con la tendencia de la educación de reducir el ángulo de visión. El profesor está llamado a enseñarle al estudiante a que se cuide de su influencia niveladora, de su deseo de adhesión. El estudiante aprenderá a cuidarse de los libros y de los profesores que forman devotos aplicados en la reverencia de sus lecturas. Nietzsche nos plantea la 
lectura como lucha que genera una tensión en el hombre. Tensión que en cierta manera tortura, y para la cual solo pocos están llamados a soportar.

Falsa apertura esto de leer demasiado. Entre novelas cortas, periódicos, revistas de entretenimiento y gacetas literarias, el hombre moderno ocupa su tiempo libre y desocupa el interés sobre sí mismo. Este interés no es lo mismo que entretenerse, evadirse u olvidarse de sí por el ruido de las noticias actuales. "El viejo analfabetismo, el de los que no sabían leer, se ve suplantado por uno nuevo: el de los que si saben y además lo hacen asidua e inescrupulosamente" (CARRIZOSA, 2000, p. 28). La lectura interesada (vale también como contemplación interesada) introduce los deseos del hombre de fundarse nuevamente. Esto supone una transición. El hombre aficionado a la lectura, empírico de la lectura, se convierte en perspectivista, en águila, en amplitud gracias a la mano formadora del gusto.

Desde Nietzsche se nos ocurre pensar al profesor como un chico que ha puesto una piedra en su cauchera. El estudiante es la piedra, el chico el profesor y la cauchera la formación. La idea es atraer la piedra hacia sí, con fuerza en un primer momento, para luego lanzarla aprovechando la elasticidad de la cauchera, la elasticidad de la formación. El profesor dispondrá libros-aventura, y toda aventura implica terrenos inexplorados, estilos que no busquen ser explícitos, que expongan sus ideas en relieve, con zonas más visibles que otras. La elección de estos textos es una incitación para el estudiante.

\section{Lectura y autodefensa}

¿Por qué considera Nietzsche necesario la autodefensa como componente de la formación del gusto por la lectura? ¿Es el instinto de autodefensa una contradicción con la apertura que antes señalábamos? Si la apertura implica exposición del lector, ¿por qué nos dice ahora Nietzsche que no debemos "revolcarnos" entre tantos libros? Lo que Nietzsche nos señala acá es una idea de lector que se debilita por exceso:

El docto, que en el fondo no hace ya otra cosa que "revolver" libros - el filólogo corriente, unos doscientos al día -, acaba de perder íntegramente y totalmente la capacidad de pensar por cuenta propia. Si no revuelve libros, no piensa. Responde a un estímulo (un pensamiento leído) cuando piensa, - al final lo único que hace ya es reaccionar [...] El instinto de 
autodefensa se ha reblandecido en él; en caso contrario se defendería contra los libros (NIETZSCHE, 1991, p. 50).

El hombre de gusto excepcional precisa de una formación que le fortalezca el instinto de autodefensa a través de la capacidad de seleccionar y rechazar. Desde la perspectiva de las fuerzas podríamos decir que la lectura activa implica una crítica, una comparación, asimilación, olvido y creación. El lector de gusto excepcional que selecciona y rechaza se pregunta: " ¿Esto que percibo es activo o reactivo?” Y a continuación se pregunta: “¿cuál es el origen de esos valores que estoy leyendo?”, “¿proviene esto del elemento apreciador o despreciador, afirmador o negador?" Es decir, lo que actualmente vamos haciendo, lo que vamos valorando no puede sustraerse a la crítica de otros valores. Tampoco podemos ser indiferentes al origen de los valores. Decir por ejemplo: "Así piensa esta disciplina, así valora esto o aquello", sin remitirnos al origen de los valores, a la piedra que sostiene sus valoraciones. La crítica del valor es lo mismo que buscar el valor de los valores. No se puede formar en la búsqueda de un origen meta-histórico, de una esencia intemporal, sino, en la necesidad de leer entrelíneas. Entiéndase por esto, identificar las máscaras, los pliegues en busca de una procedencia, del devenir del pensamiento.

Al ser el acto de lectura una inscripción sobre el cuerpo más o menos profundo, más o menos superficial, es la propia vida la que se pone en juego en esta percepción de valores. La lectura nos conforma, nos ofrece una visión de mundo por lo cual el estudiante no puede pensar un libro como un objeto sin poder, neutral, o aun más ingenuo, como una palabra muerta. Cuando el cuerpo se vuelve selectivo con los libros comprende cómo él mismo responde a las lecturas mediocres. No es un asunto que hay que pasar por alto. El cuerpo debe aprender a reaccionar, a distinguir los síntomas de su repulsión, a defenderse como se defiende de cualquier otra cosa que lo perjudique. Para Nietzsche, la lectura motiva el pensar, seguir girando en torno a la lectura después de haberla realizado. La lectura da qué pensar, nos hace reflexivos, profundos. Se sabe que la lectura tiene pliegues, máscaras por develar. Por eso debemos entender que leer es siempre interpretar una interpretación. Nietzsche nos invita a no leer al pie de la letra, entregándonos por completo al texto como si fuera una realidad definitiva, plana e intemporal. Es un error separar el libro de sus condiciones, de la cultura que lo rodeó y de la tendencia del pensamiento de su época. Los libros están llenos de giros, de quiebres y silencios, malos cálculos o faltas de apreciación. Leer así permite identificar que el punto de eclosión no es sólido, ni puro, ni verdadero, sino la exterioridad del accidente. 


\section{REFERÊNCIAS}

NIETZSCHE, Friedrich. Asi habló Zaratustra. España: Alianza Editorial, 1978. . Sobre el porvenir de nuestras escuelas. Barcelona: Tusquets, 1980. . La voluntad de poderío. Madrid: Edaf, 1981. . El anticristo; cómo se filosofa a martillazos. España: Edaf, 1983. . Ecce homo. Madrid: Alianza editorial, 1991. . Fragmentos póstumos. Santafé de Bogotá: Norma, 1992. . Más allá del bien y del mal. Madrid: Alianza Editorial, 1997. . Genealogía de la moral. Valencia: Universidad de Valencia, 1998. torial, 2000 . . El nacimiento de la tragedia. O Grecia y el pesimismo. Madrid: Alianza Edi. Schopenhauer como educador. Madrid: Biblioteca Nueva, 2000a. . La gaya ciencia. México: Editores Mexicanos Unidos, S.A., 2001. . Sobre la utilidad y el perjuicio de la historia para la vida. Madrid: Biblioteca Nueva, 2003. . La voluntad de poder. Madrid: Edaf, 2005. . El caminante y su sombra. España: Edimat Libros, 2005a. . Humano, demasiado humano. Madrid: Edaf, $2005 \mathrm{~b}$. . Fragmentos póstumos. España: Tecnos, 2008.

\section{Fuente secundaria}

BETANCOURT, W. Nietzsche: filosofía y educación. Praxis Filosófica, Universidad del Valle, Cali, n. 28, p. 23-54, enero-junio 2009.

CARRIZOSA, D. Nietzsche: La educación como formación del gusto. Revista Educación y Pedagogía, n. 26-27, p. 23-36, 2000.

DE SANTIAGO, L. Arte e historia en F. Nietzsche: una estética de la historia. Contrastes: Revista Internacional de Filosofía, Málaga, vol. 10, p. 99-118, 2005.

DELEUZE, G. Nietzsche y la filosofia. Barcelona: Anagrama, 2008. ; GUATTARI, F. Qué es la filosofía. Barcelona: Anagrama, 1994.

DESIATO, M. La complicidad del cuerpo. Ideas y Valores, Bogotá, n. 114,p. 65-82, 2000. 
FOUCAULT, M. Nietzsche, la genealogía, la historia. Valencia: Pre-Textos, 1992.

GALLO, Luz. Los discursos de la Educación Física contemporánea. Bogotá: Kinesis, 2010.

GARCÍA, C.; CORREA, A. Educación Corporal o el preludio del valor superior del cuerpo. Medellín: Universidad de Antioquia. Proyecto de investigación sin publicar. 2010.

JARA, José. Nietzsche, un pensador póstumo. El cuerpo como centro de gravedad. Anthropos. Chile, 1998.

JASPERS, K. Nietzsche. Introducción a la comprensión de su filosofar. Buenos Aires, Argentina: Suramericana, 2003.

LARROSA, Jorge. La experiencia de la lectura: estudios sobre literatura y formación. Laertes. España, 1996.

ROCHA, Alfredo de la Torre. El cuerpo como centro de interpretación. Una aproximación a la concepción nietzscheana. Universitas Philosophica, Santafe de Bogotá, V. 17, n. 34-35, 2000.

ROSS, W. Nietzsche. El águila angustiada. Una biografía. España: Paidos Testimonios, 1994.

SONTAG, S. Contra la interpretación y otros ensayos. España: Seix Barral, 2007.

\section{Cibergrafía}

SALCIDO, M. Nietzsche filólogo. Ambivalencias de una Grecia subterránea. Signos Filosóficos. 2008. Disponible en: <http://148.206.53.230/revistasuam/signosfilosoficos/ include/getdoc.php $? \mathrm{id}=574 \&$ article $=405 \&$ mode $=$ pdf $>$. Recuperado el 15/12/2010.

Texto recebido em 28 de maio de 2011.

Texto aprovado em 19 de abril de 2012. 